\title{
CAN RBC MODELS EXPLAIN BUSINESS CYCLES IN KOREA?
}

\author{
WOOHEON RHEE \\ Kyung Hee University
}

I examine whether an RBC model can generate a higher volatility of consumption relative to output, a strong negative correlation between output and the trade balance, and a weak countercyclicality of the real interest rate, phenomena that have been observed in the business cycles of emerging economies, including Korea. From an RBC model with recursive utility, I show that it is not the degree of relative risk aversion, but the elasticity of intertemporal substitution (EIS), that governs the movements of the variables of the model in the log linearized environment. The Bayesian estimation results based on Korean data from the period 1987 to 2013 suggest that there are some elements of success in describing the Korean economy based on the simple RBC model both with the EIS larger than one and with an error term for the real interest rate equation. An EIS larger than one improves the performance of the simple RBC model mainly in the direction of raising the volatility of consumption relative to output. Simulation results show that the error term for the real interest rate process mostly reflects the endogenous channel of financial frictions where the domestic real interest rate depends negatively on the expected (transitory) productivity shock.

Keywords: RBC Model, Emerging-Economy Business Cycles, Korean Economy, Recursive Utility, Elasticity of Intertemporal Substitution

\section{INTRODUCTION}

Some researchers have recently observed that business cycles in emerging economies can be characterized very differently from those in advanced economies. For example, in emerging economies, consumption is relatively more volatile than output, the trade balance is strongly countercyclical, and the cost of foreign borrowing is countercyclical. ${ }^{1}$ I will call these the stylized facts in emergingeconomy business cycles.

Notably, Aguiar and Gopinath (2007; henceforth AG) showed that the standard RBC model with a growth shock can successfully explain the stylized facts in emerging-economy business cycles. AG argue that a shock to the growth rate leads to an even larger increase in future income, implying that consumption responds more than current period income, reducing savings and generating a

I benefited from helpful comments by two anonymous referees, Sungbae An, Hong-Ki Bahng, Yongsung Chang, Yongseung Jung, Jinill Kim, Siwon Ryu, Myung-Soo Yi, Tack Yun, and seminar participants at the 2012 JSIE meeting. Any errors are mine. Address correspondence to: Wooheon Rhee, Department of Economics, Kyung Hee University, 25 Kyungheedae-ro, Dongdaemun-gu, Seoul 130-701, Korea; e-mail: wrhee@khu.ac.kr. 
large trade deficit. In contrast, if the shock is transitory, agents will increase savings. Consumption will increase by less and the trade balance will deteriorate by less or even improve.

Previous research on emerging-economy business cycles examines Korean data when pointing out the stylized facts, but estimations and discussions mainly focus on Latin American economies such as Mexico and Argentina. Thus, examining the issue based explicitly on Korean data both in calibration and in estimation would fill a gap in the literature, which is one of the aims of this paper.

In order to examine the issue, I employ the recursive utility of Epstein and Zin (1991) and Weil (1989) instead of the CRRA utility function commonly used in the literature on emerging-economy business cycles. It is well known that the degree of relative risk aversion equals the inverse of the elasticity of intertemporal substitution (EIS hereafter) in the CRRA utility function, and they are not disentangled. If we stick to the conventional interpretation of the CRRA utility function, and if we set the degree of relative risk aversion at two to four, commonly used in the literature, we have a situation where the discount factor is greater than one in the Korean data. Specifically, as I show in Section 3, the CRRA utility function implies that the real interest rate $(1+r)$ in the steady state equals $g^{\gamma} / \beta$, where $\gamma$ denotes the degree of relative risk aversion, and $g$ represents the steady state value of the (gross) growth rate. Put differently, $\beta=g^{\gamma} /(1+r)$. Unless the mean growth rate is far less than the steady state value of the real interest rate, $\beta$ (the discount factor) is greater than one. Unfortunately in the Korean data, the mean growth rate of real GDP is slightly less than the highest measure of the mean real interest rate for the sample period. ${ }^{2}$ Therefore, we should fix $\gamma$ at one in order to have $\beta$ less than one, if we stick to the conventional interpretation of the CRRA utility function. Even in this case, $\beta$ turns out to be 0.9985 in the Korean data, which is virtually one.

The recursive utility (RU) of Epstein and Zin (1991) and Weil (1989) separates the degree of relative risk aversion from the EIS. Log linearization of the model with recursive utility shows that it is not the degree of relative risk aversion but the elasticity of intertemporal substitution that governs the movements of the log linearized system of the model. It is the EIS that governs the movements of the stochastic discount factor. The steady state value of the real interest rate and all the $\log$ linearized equations are governed by the EIS — not by the measure of relative risk aversion. This means that the RBC model with recursive utility is seemingly equivalent to the same model with the CRRA utility function in the log linearized environment. However, the interpretation of the model parameter $\gamma$, the degree of relative risk aversion in the CRRA utility function, might be different: it represents not the degree of relative risk aversion but the inverse of the EIS. This allows us to set $\gamma$, conventionally interpreted as the meaure of relative risk aversion, to a value less than one, implying an EIS greater than one. ${ }^{3}$

I calibrate a model based on Korean data for the period 1987-2013 and do a Bayesian estimation of the model. The estimation and simulation results suggest that it is fair to say that a simple RBC model both with the EIS greater than one 
and with an error term for the real interest rate equation can reasonably explain the business cycle stylized facts in the Korean economy despite its simplicity. It explains the excess volatility of consumption relative to output. The simulated volatility of consumption relative to output is 1.22 , and close to the actual number from the data, 1.25. It also shows a weak countercyclicality (or acyclicality) of the real interest rate.

I set the prior mean of the EIS at 2.3 in the Bayesian estimation of the model with recursive utility, which is equivalent to setting $\gamma$ to $1 / 2.3$ in the log linearized model with the CRRA utility function. The relative success of the RBC model with recursive utility, coupled with the EIS larger than one, or, equivalently, the model with the CRRA utility function, combined with $\gamma$ less than one, suggests that it is the EIS, not the coefficient of relative risk aversion, that contributes most to the increase in the relative volatility of consumption in the model. We can understand this easily if we recall that the degree of risk aversion reflects intratemporal substitution across states, whereas the EIS reflects the intertemporal substitution across time. A higher EIS implies a higher volatility of consumption if other things are equal.

I also include an error term for the real interest rate equation. It can be interpreted as either reflecting some aspects of financial frictions or representing a measurement error independent of them. Some researchers argue for the importance of incorporating some aspects of financial frictions into the standard RBC model in order to explain the stylized facts in emerging-economy business cycles. For example, Neumeyer and Perri (2005), Uribe and Yue (2006), Garcia-Cicco et al. (2010), and Chang and Fernandez (2013) argue for the importance of interest rate shocks and financial frictions in explaining the stylized facts in emerging-economy business cycles. The estimation results confirm that this is also the case in Korea. Interest rate shocks are important in explaining the stylized facts in Korean business cycles. The error term for the real interest rate equation turns out to reflect mostly the endogenous channel of financial frictions, where the domestic real interest rate depends negatively on the expected (transitory) productivity shock. The estimation results further imply that the contribution of the trend component is small (about six percent) in explaining the movements of output.

In Section 2, I discuss some aspects of the Korean business cycles along with fluctuations in productivity. The data show that the excess volatility of consumption relative to output is mainly due to market conditions in the 1990s and 2000s. In Section 3, I introduce the simple RBC model with a growth shock proposed by AG and Garcia-Cicco et al. (2010) and discuss some issues in matching the implications of the model with the Korean data. I then incorporate the recursive utility of Epstein and Zin (1991) and Weil (1989) into the simple RBC model in order to show that it is the EIS, not the degree of relative risk aversion, that governs the movements of the log linearized system of the model. In Section 4, I describe the Korean data, present the Bayesian estimation results from the baseline RBC model, both with the EIS larger than one and with an error term for the real interest rate equation, and discuss the importance of the trend component. In order 


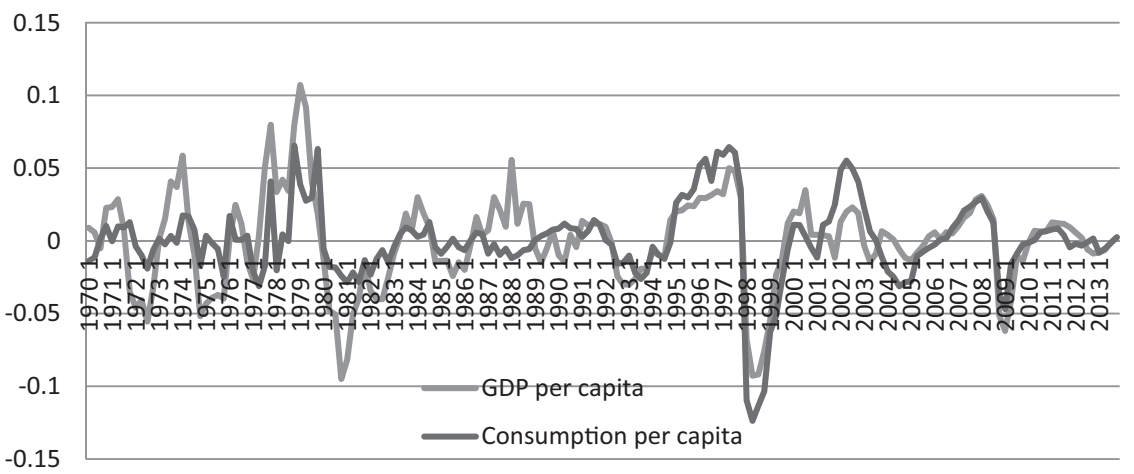

FIGURE 1. Business cycles in Korea.

to examine whether the error term for the real interest rate equation reflects some aspects of financial frictions, or whether it represents a simple measurement error independent of them, I do some additional analyses on RBC models with various aspects of financial frictions in Section 5. I examine whether the main message of this paper - that the higher EIS can explain the excess volatility of consumption relative to output — can be applied to the Argentine economy in Section 6. I also examine whether taking the risky steady state into consideration can improve the performance of the simple RBC model in explaining the excess volatility of consumption relative to output in Section 7. Section 8 briefly concludes.

\section{SOME REMARKS ON KOREAN BUSINESS CYCLES}

Previous research shows that the Korean economy exhibits excess volatility of consumption relative to output, as do other emerging economies. For example, AG's Table 2B reports that the volatility of consumption relative to output is 1.23 in the case of Korea. However, it is worthwhile to note that consumption is not always more volatile than output throughout the AG's sample period (79:IV03:II). The excess volatility of consumption relative to output is due to the fact that consumption is more volatile than output only for the latter part of the sample, the 1990s and 2000s. More specifically, the volatility of consumption relative to output is $0.82(0.85)$ for the sample period between 79:IV and 86:IV (95:IV). It increases and becomes higher than one as the latter part of the sample is included. ${ }^{4}$

Figure 1 shows log GDP per capita and log consumption per capita in Korea for the period 1970:I-2013:IV, for which official GDP data published by the Bank of Korea are available. The source of the data will be discussed in Subsection 4.1. Log GDP per capita and log consumption per capita are HP-filtered with a smoothing parameter of 1600 . One thing we have to note in Figure 1 is that consumption is no longer more volatile than output for the sample period as a whole. The volatility of consumption relative to output is 0.88 . However, when the sample covers the period between $87: \mathrm{I}(93: \mathrm{I})$ and $13: \mathrm{IV}$, it rises to $1.25(1.33){ }^{5}$ 
TABLE 1. Business cycle reference dates and the average growth rates of TFP in Korea: 1970-2013

\begin{tabular}{clllcr}
\hline Cycle & \multicolumn{1}{c}{ Trough } & \multicolumn{1}{c}{ Peak } & \multicolumn{1}{c}{ Trough } & $\begin{array}{c}\text { Length } \\
\text { (months) }\end{array}$ & $\begin{array}{c}\text { Average of TFP } \\
\text { growth rates }\end{array}$ \\
\hline 1 & Mar. 1972 & Feb. 1974 & Jun. 1975 & 39 & 0.07 \\
2 & Jun. 1975 & Feb. 1979 & Sep. 1980 & 63 & -0.04 \\
3 & Sep. 1980 & Feb. 1984 & Sep. 1985 & 60 & 0.26 \\
4 & Sep. 1985 & Jan. 1988 & Jul. 1989 & 46 & 0.26 \\
5 & Jul. 1989 & Jan. 1992 & Jan. 1993 & 42 & 0.28 \\
6 & Jan. 1993 & Mar. 1996 & Aug. 1998 & 67 & -0.05 \\
7 & Aug. 1998 & Aug. 2000 & Jul. 2001 & 35 & 0.17 \\
8 & Jul. 2001 & Dec. 2002 & Apr. 2005 & 45 & 0.31 \\
9 & Apr. 2005 & Jan. 2008 & Feb. 2009 & 46 & 0.33 \\
10 & Feb. 2009 & Aug. 2011 & 2nd half of 2012* & & 0.44 \\
11 & 2nd half of 2012* & & & & \\
\hline
\end{tabular}

* This is preliminary and not yet officially confirmed by Statistics Korea.

This fact suggests that we would best use a shorter sample rather than the whole sample as far as the Korean data are concerned in examining whether RBC models can explain the stylized facts in emerging-economy business cycles such as excess volatility of consumption relative to output. Another reason we should use a shorter rather than the whole sample is that we have little official data on interest rates, reflecting market conditions until the 1990s. Almost no official interest rate data are available for the earlier part of the sample. The Bank of Korea does not publish interest rate data for the earlier period, mainly because both deposit and lending interest rates were controlled by the government and do not reflect market conditions. One interest rate that provides the longest series and, at the same time, reflects market conditions is the rate for $\mathrm{AA}-$ rated corporate bonds $[\mathrm{CB}(\mathrm{AA}-)]$, and data on this interest rate are available only since 1987.

There is a cost in using a shorter rather than the whole sample, however. There may not be enough trend (or business) cycles to analyze in the short data sample. Statistics Korea is in charge of dating the official business cycle reference dates in Korea. They are reported in Table 1 . There were eleven business cycles for the period between 1970 and 2013, and seven cycles for the period between 1987:I and 2013:IV. It suggests that if we use the data for the period between 1987:I and 2013:IV, we have data for seven business cycles (fourth to eleventh cycles since 1970).

In order to have some idea about the fluctuations in productivity in Korea for the sample period, I calculate total factor productivity (henceforth, TFP) for the period 1970 to 2011 . The TFP is obtained as

$$
\mathrm{TFP}_{t}=\log \left(Y_{t}\right)-\alpha \log \left(K_{t}\right)-(1-\alpha) \log \left(h_{t}\right),
$$

where $Y_{t}$ and $h_{t}$ denote output and work hours in period $t$, and $K_{t}$ denotes the capital stock at the beginning of period $t$. The parameter $\alpha$ denotes the capital share 


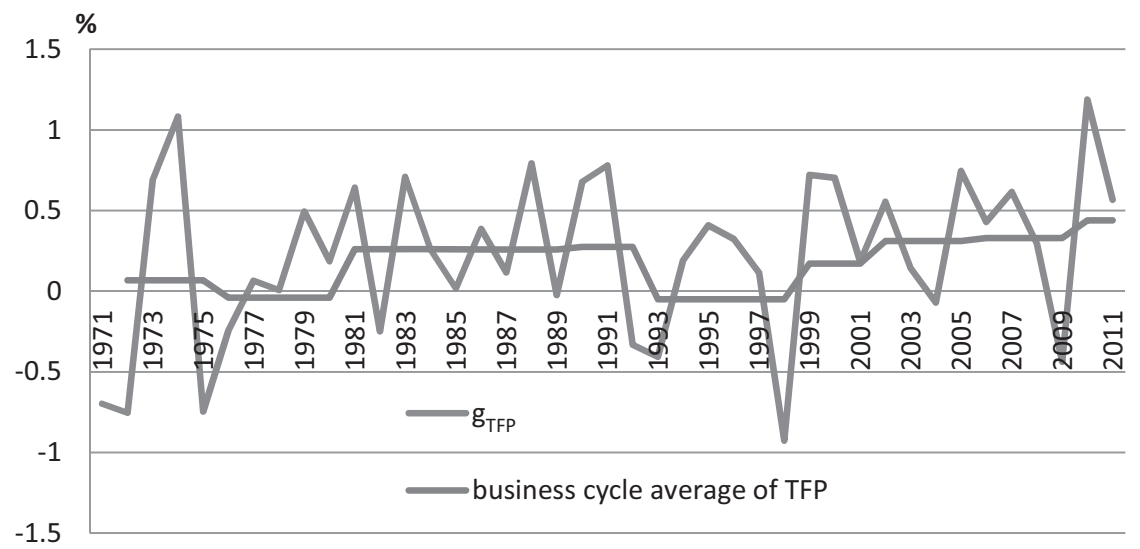

FIGURE 2. Growth rates of TFP $\left(g_{\text {TFP }}\right)$ : 1971-2011.

in output. All the data used to calculate TFP are annual, in 2000 prices, and are available from the Korea Productivity Center (http://www.kpc.or.kr/productivity/). Of course, TFP measured in this way includes both the transitory and growth components of productivity. I do not try to separate them here using a time series estimation technique such as that in King et al. (1991). Instead, I report the importance of the growth component in Subsection 4.3 based on the Bayesian estimation results of the model.

Figure 2 shows the growth rates of total factor productivity (TFP) for the period 1971-2011 and the averages of TFP growth rates for each business cycle reported in Table 1. Growth rates of TFP fluctuate a lot and the average of TFP growth rates falls below zero during the second (75:II-80:III) and sixth (93:I-98:III) business cycles. The fall in the second business cycle seems to be related to the first and second oil shocks and the fall in the sixth business cycle seems to be related to the occurrence of the Asian currency crisis in 1997. After the first fall, the average TFP growth rate goes up and fluctuates around $0.26 \%$ during the third to fifth business cycles. After the second fall, it continuously increases from $0.17 \%$ during the seventh cycle to $0.44 \%$ during the tenth business cycle. Thus, there appear to be about five trend cycles for the whole sample for which official national accounting data are available and three trend cycles for the shorter sample (87:I-11:IV) in terms of the average growth rates of TFP. ${ }^{6}$

\section{THE MODEL}

\subsection{The Standard RBC Model}

Here, I introduce the simple RBC model with a growth shock proposed by AG and Garcia-Cicco et al. (2010), among others. The production function takes a 
Cobb-Douglas form with the labor-augmenting technology

$$
Y_{t}=a_{t} K_{t}^{\alpha}\left(X_{t} h_{t}\right)^{1-\alpha}
$$

The natural logarithm of the transitory productivity shock, $a_{t}$, follows a first-order autoregressive process,

$$
\ln a_{t}=\rho_{A} \ln a_{t-1}+\varepsilon_{A t},-1<\rho_{A}<1,
$$

with $\varepsilon_{A t} \sim N\left(0, \sigma_{A}\right)$. The natural logarithm of the growth rate, $g_{t} \equiv \frac{X_{t}}{X_{t-1}}$, of the trend component, $X_{t}$, follows an AR(1) process,

$$
\ln \left(g_{t+1} / g\right)=\rho_{g} \ln \left(g_{t} / g\right)+\varepsilon_{g t+1},-1<\rho_{g}<1,
$$

where $g$ denotes the mean of $g_{t}$ and $\varepsilon_{g t} \sim N\left(0, \sigma_{g}\right)$. The equation of motion for the capital stock is given by

$$
K_{t+1}=(1-\delta) K_{t}+I_{t}
$$

where $I_{t}$ and $\delta$ denote investment in period $t$ and the depreciation rate, respectively. The budget constraint of a representative agent is given by

$$
D_{t}+C_{t}+I_{t}+\frac{\kappa}{2}\left(\frac{K_{t+1}}{K_{t}}-g\right)^{2} K_{t}=Y_{t}+\frac{D_{t+1}}{1+r_{t}},
$$

where $D_{t+1}$ denotes the bond issued in period $t$ at a discount rate of $r_{t} . C_{t}$ is consumption in period $t$. The parameter $\kappa$ measures the level of adjustment costs. The domestic real interest rate, $r_{t}$, is the sum of the foreign interest rate $\left(r^{*}\right)$ and the risk premium, $\phi\left(\exp \left(\widetilde{D}_{t} / X_{t}-\bar{d}\right)-1\right)$, and

$$
Q_{t}^{-1} \equiv 1+r_{t}=1+r^{*}+\phi\left(\exp \left(\widetilde{D}_{t} / X_{t}-\bar{d}\right)-1\right)
$$

where $\widetilde{D}_{t}$ is the aggregate level of external debt per capita, which the agent takes as exogenous. At equilibrium, $D_{t}=\widetilde{D}_{t}$. The parameter $\bar{d}$ represents the mean external debt per capita. I assume that $r_{t}^{*}$ is constant, following Otsu (2008) and Garcia-Cicco et al. (2010). The variable $Q_{t}$ is defined as the inverse of the gross real interest rate.

The representative agent's utility function takes the Cobb-Douglas form and she solves the following problem subject to the budget constraint (6):

$$
\operatorname{Max} E_{0} \sum_{t=0}^{\infty} \beta^{t} \frac{C_{t}^{1-\gamma}-1}{1-\gamma}
$$

where $\gamma$ represents both the degree of relative risk aversion and the inverse of the elasticity of intertemporal substitution. Note that the utility function in (8) does not have work hours in it. I will explain why I do not consider work hours in this paper in detail in Subsection 3.3. 
The first-order conditions with respect to $c_{t}, d_{t}, k_{t+1}$ in stationary forms (divided by $X_{t-1}$, and expressed in lowercase letters) are

$$
\begin{gathered}
c_{t}^{-\gamma}=\lambda_{t}, \\
\lambda_{t}=\beta \frac{\left[1+r^{*}+\psi\left(e^{d_{t}-\bar{d}}-1\right)\right]}{g_{t}^{\gamma}} E_{t} \lambda_{t+1}, \\
{\left[1+\kappa\left(\frac{k_{t+1}}{k_{t}} g_{t}-g\right)\right] \lambda_{t}} \\
=\frac{\beta}{g_{t}^{\gamma}} E_{t} \lambda_{t+1}\left[\begin{array}{c}
1-\delta+\alpha a_{t+1}\left(\frac{g_{t+1} h_{t+1}}{k_{t+1}}\right)^{1-\alpha} \\
\left.+\kappa\left(\frac{k_{t+2}}{k_{t+1}} g_{t+1}\right)\left(\frac{k_{t+2}}{k_{t+1}} g_{t+1}-g\right)-\frac{\kappa}{2}\left(\frac{k_{t+2}}{k_{t+1}} g_{t+1}-g\right)^{2}\right],
\end{array}\right.
\end{gathered}
$$

where $\lambda_{t}$ represents the Lagrange multiplier for the budget constraint facing the household. Equation (9) states that the Lagrange multiplier represents the marginal utility of consumption. Equations (10) and (11) are the usual Euler equation and the capital Euler equation, respectively.

The remaining equilibrium conditions are

$$
\begin{gathered}
d_{t}+c_{t}+i_{t}+\frac{\kappa}{2}\left(\frac{k_{t+1}}{k_{t}} g_{t}-g\right)^{2} k_{t}=y_{t}+\frac{d_{t+1}}{1+r_{t}} g_{t}, \\
r_{t}=r^{*}+\psi\left(e^{d_{t}-\bar{d}}-1\right), \\
k_{t+1} g_{t}=(1-\delta) k_{t}+i_{t}, \\
y_{t}=a_{t} k_{t}^{\alpha}\left(g_{t} h_{t}\right)^{1-\alpha} .
\end{gathered}
$$

For later use, trade balance $(t b)$ is defined as

$$
t b_{t}=d_{t}-\frac{d_{t+1}}{1+r_{t}} g_{t} .
$$

\subsection{Real Interest Rates in Korea}

Before we proceed, let me point out that, in order to explain movements in the real interest rate in Korea, we need to assume a relatively lower discount rate (or relatively higher value of $\beta$ ) than for other emerging economies such as Mexico and Argentina, which have been the main focus of the recent literature. We need to make this supposition because the sample mean (gross) growth rate, $g$, is large relative to the sample mean (gross) real interest rate $(1+r)$. 


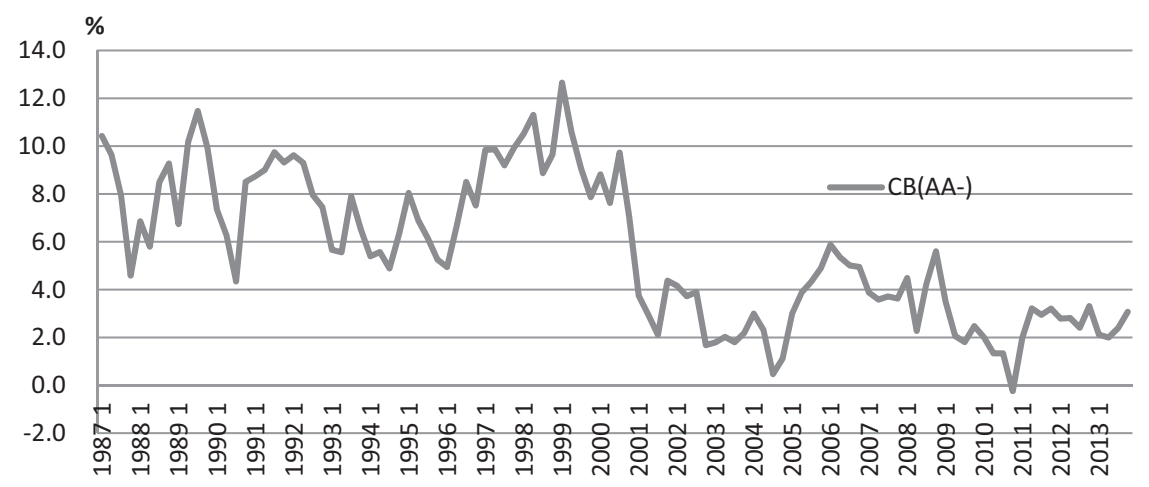

FIGURE 3. The real interest rate in Korea.

From equations (10) and (13), we know that the (net) real interest rate in the steady state is given by

$$
r=r^{*}=\frac{g^{\gamma}}{\beta}-1 .
$$

This can be rewritten as

$$
\beta=\frac{g^{\gamma}}{1+r}
$$

Equation (18) suggests that the discount factor $\beta$ should be greater than one if the steady state value of the mean (gross) growth rate, $g$, is large relative to the steady state (gross) real interest rate, $(1+r)$. Other things equal, the lower the steady state value of the real interest rate, the higher the discount factor. Thus we need a measure of the real interest rate that is large relative to the steady state value of the mean (gross) growth rate, $g$, in order to avoid a situation where the discount factor $\beta$ is larger than one.

Figure 3 plots the real interest rate in Korea for the sample period 1987:I2013:IV. In the figure, the real interest rate is calculated as the difference between the nominal interest rate for $\mathrm{AA}-$ rated corporate bonds $[\mathrm{CB}(\mathrm{AA}-)]$ and the four-quarter moving average of the GDP deflator inflation rates. This choice is restricted by the availability of data for the sample and the representativeness of market conditions. This measure of the real interest rate fluctuates between $6 \%$ and $13 \%$ during the first half of the sample and peaks in the second quarter of 1998, during which time the IMF and the Korean government agreed to switch from a high-interest-rate policy to a more modest interest-rate policy. After that it tends to go down and stays below $4 \%$ for most of the period, except for the credit crunch in 2002 and the initial stage of the financial crisis in 2008. The average annual real interest rate is $5.47 \%$ for the sample period.

We should note that even this measure of the average quarterly real interest rate $(1.37 \%)$ reported in Figure 3 is much lower than the values implied by AG (the quarterly rate of 3.4\% for Mexico) and Garcia-Cicco et al. (2010) (the annual rate 
of $9.5 \%$ for Argentina). This restricts our choice of values for $\gamma$, which measures the degree of relative risk aversion. The most commonly accepted values for $\gamma$ range from two to four in the business cycle research. It is thought to be much larger than that if our main focus is on explaining movements in financial variables. The fact that the sample mean of the real interest rate is relatively low in Korea restricts the choice of the value for $\gamma$ to one or less. More specifically, the average quarterly (gross) growth rate of GDP per capita, $g$, for the sample is 1.0122, and the average quarterly gross real interest rate, $1+r$, is 1.0137 . If the exponent of the preference, $\gamma$, equals two, then the discount factor $(\beta)$ calculated from equation (18) is 1.01 and is larger than one. Thus, I need to fix the parameter $\gamma$ at one or a value less than one in order not to have the discount factor be larger than one and to let $\beta$ be determined at the level that satisfies the steady state equilibrium condition (18). Even in the case of $\gamma=1, \beta$ turns out to be 0.9985 . This is virtually one.

\subsection{The Model with Recursive Utility}

Unlike the previous research in this area, I employ the recursive utility of Epstein and Zin (1991) and Weil (1989) in explaining the stylized facts in emergingeconomy business cycles. One advantage of using this type of utility is that we can separate the degree of (relative) risk aversion from the EIS. As is well known, the CRRA utility function does not disentangle the two parameters. The degree of relative risk aversion equals the inverse of the EIS in the CRRA utility function.

I assume that the agent's objective function is given by

$$
V_{t}=\left\{(1-\beta) C_{t}^{\frac{1-\gamma}{\theta}}+\beta\left[E_{t}\left(V_{t+1}^{1-\gamma}\right)\right]^{\frac{1}{\theta}}\right\}^{\frac{\theta}{1-\gamma}},
$$

where $\theta \equiv \frac{1-\gamma}{1-1 / \psi}$, and the parameters $\gamma$ and $\psi$ represent the degree of relative risk aversion and the EIS, respectively. If $\gamma=\frac{1}{\psi}$, and $\theta=1$, the objective function $V_{t}$ collapses to the usual CRRA utility fuction. The specific form of the value function in (19) is borrowed from Dew-Becker (2012) and Chen et al. (2013), among others, though their main focus is not (emerging-economy) business cycles.

The stochastic discount factor and the Euler equation in stationary forms are given by

$$
m_{t, t+1} \equiv \beta E_{t}\left\{\left(\frac{c_{t+1}}{c_{t}} g_{t}\right)^{\frac{1-\gamma-\theta}{\theta}} \frac{\left(v_{t+1} g_{t}\right)^{\frac{(\theta-1)(1-\gamma)}{\theta}}}{\left[E_{t}\left(v_{t+1} g_{t}\right)^{1-\gamma}\right]^{\frac{\theta-1}{\theta}}}\right\}
$$

and

$$
1=E_{t}\left\{\beta\left(\frac{c_{t+1}}{c_{t}} g_{t}\right)^{\frac{1-\gamma-\theta}{\theta}} \frac{\left(v_{t+1} g_{t}\right)^{\frac{(\theta-1)(1-\gamma)}{\theta}}}{\left[E_{t}\left(v_{t+1} g_{t}\right)^{1-\gamma}\right]^{\frac{\theta-1}{\theta}}}\left(1+r_{t}\right)\right\},
$$

respectively. 
Note that the value function in (19) does not have work hours in it. The reason I do not consider the labor market in this paper is that it is known that the simple RBC model with a growth shock presented in Subsection 3.1 does not satisfactorily explain the stylized facts in emerging-economy labor markets: large fluctuations in wages and subdued fluctuations in employment. Refer to Bahng (2012) and Boz et al. (2012) for the detailed discussions and references therein. Another reason I do not include work hours in the utility function is to remove the interaction between consumption and labor. If the period utility depends nonseparably on both consumption and labor, the marginal utility of consumption depends on labor. Furthermore, even if consumption and labor are separable in the period utility, the stochastic discount factor is affected by labor through the value function for the next period, $V_{t+1}$, as noted in Dew-Becker (2014).

The main purpose of this paper is to examine whether the simple RBC model with recursive utility can generate a higher volatility of consumption relative to output, a strong negative correlation between output and the trade balance, and a weak countercyclicality of the real interest rate-phenomena that have been observed in Korean business cycles. For that reason, I assume that the labor supply is inelastically fixed at unity. Then the production function (15) is given by

$$
y_{t}=a_{t} k_{t}^{\alpha}\left(g_{t}\right)^{1-\alpha} .
$$

The use of recursive utility also changes the capital Euler equation:

$$
\begin{aligned}
& {\left[1+\kappa\left(\frac{k_{t+1}}{k_{t}} g_{t}-g\right)\right]} \\
& \quad=E_{t}\left\{m_{t, t+1}\left[\begin{array}{c}
1-\delta+\alpha a_{t+1}\left(\frac{g_{t+1}}{k_{t+1}}\right)^{1-\alpha} \\
+\kappa\left(\frac{k_{t+2}}{k_{t+1}} g_{t+1}\right)\left(\frac{k_{t+2}}{k_{t+1}} g_{t+1}-g\right)-\frac{\kappa}{2}\left(\frac{k_{t+2}}{k_{t+1}} g_{t+1}-g\right)^{2}
\end{array}\right]\right\} .
\end{aligned}
$$

The remaining equilibrium conditions are equations (12)-(14). I will call the model described in this subsection the baseline model.

For later use, let us derive the real interest rate in the steady state when we employ recursive utility. From the Euler equation (21), we know that the steady state level of the (net) real interest rate is given by

$$
r=r^{*}=\frac{g^{(\gamma+\theta-1) / \theta}}{\beta}-1,
$$

which implies that

$$
\beta=\frac{g^{1+(\gamma-1) / \theta}}{1+r}=\frac{g^{1 / \psi}}{1+r} .
$$

The second equality follows from the definition of $\theta$. From this equation, we know that the steady state value of the real interest rate is not governed by the degree of 
relative risk aversion but by the EIS. This implies that we do not have to set the value of $\gamma$ at a very restrictive value of one in order to calibrate the model with the Korean data.

In addition, the log linearization of the model reveals an interesting feature that has not been emphasized in previous work. For example, the log linearization of the stochastic discount factor (20) is given by

$$
E_{t}\left[\widehat{m}_{t, t+1}\right]=E_{t}\left[-\frac{1}{\psi}\left(\widehat{c}_{t+1}-\widehat{c}_{t}+\widehat{g}_{t}\right)\right],
$$

and the log linearization of the Euler equation (21) is given by

$$
E_{t}\left[\widehat{m}_{t, t+1}-\widehat{q}_{t}\right]=0,
$$

where $\widehat{q}_{t}$ denotes the $\log$ linearized $Q_{t} \equiv \frac{1}{1+r_{t}}$. This shows that it is not the degree of relative risk aversion but the EIS that governs the movements of the log linearized system of the model.

The conventional log linearized stochastic discount factor in the case of the CRRA utility function simply replaces $\frac{1}{\psi}$ with $\gamma$ in equation (26). Thus, the $\log$ linearized RBC model with recursive utility is seemingly equivalent to the same model with the CRRA utility function. However, the interpretation of the model parameter $\gamma$, the degree of relative risk aversion and, at the same time, the inverse of the EIS, in the CRRA utility function might be different: it represents the inverse of the EIS, not the degree of relative risk aversion in the log linearized environment. This allows us to set $\gamma$, conventionally interpreted as the measure of relative risk aversion, to a value less than one, implying that the EIS is larger than one. I will come back to this point in Subsection 4.2.

\section{DATA AND ESTIMATION RESULTS}

Now I turn to a discussion of the Korean data and the estimation methods.

\subsection{Data and Calibration}

All the national accounting data are from the Economic Statistics System of the Bank of Korea (http://ecos.bok.or.kr). As measures of real output, consumption, investment, and the trade balance, I use the logarithm of real GDP net of government spending, the logarithm of private consumption, the logarithm of total capital formation, and the level of the trade balance, respectively. They are all in the series 10.4.2.2 of the Economic Statistics System of the Bank of Korea. As is well known, Korea has experienced dramatic changes in demography over the sample period. The population growth rate is falling, and the society is aging very rapidly. However, the model in Section 3 does not consider labor supply, let alone population growth. Examining the effect of population dynamics on the Korean economy is itself a very important issue and it is beyond the scope 
of this paper. Thus, I transform all the variables into per capita variables. All the relevant variables are divided by the population measure used by the Bank of Korea to get the per capita values. The population data are from the Korean Statistical Information Service (KOSIS). All the data are HP-filtered in order to have stationary series and the smoothing parameter is set to 1600 .

The sample period is 1987:I-2013:IV. As explained in Section 2, this period is chosen for several reasons. First, the excess volatility of consumption relative to output is not a prominent phenomenon in Korean business cycles before the Asian currency crisis of 1997. The volatility of consumption relative to output for the period 1970-1995 is just 0.51. Consumption was much smoother than output for the period, as it is in advanced economies. Second, the Korean government liberalized the financial market in the early 1990s and has let the interest rate be determined in the market step by step since 1992. Before then, interest rates were controlled by the government. The longest market interest rate series that the Bank of Korea officially publishes is the rate for AA- rated corporate bonds; this series has been available since January 1987. Third, the period includes two crises: the Asian currency crisis in 1997 and the global financial crisis in 2008. The two crises contributed to the excess volatility of consumption relative to output. ${ }^{7}$

For the sample period, the average quarterly growth rate $(g)$ of real GDP net of government spending in Korea is set to $1.2 \%$. The average quarterly net real interest rate $(r)$ for the sample period is set to $1.4 \%$. Real interest rates are constructed as the difference between the AA- corporate bond yields (series 4.2.2.1) and the four-quarter moving average of the GDP deflator inflation rate (series 10.4.3.2). I set the capital coefficient at $\alpha=0.4$, based on the fact that the labor income share (series 10.1.1) in the Korean economy, measured as the ratio of compensation for employees to GDP for the period 1987 to 2013, fluctuates around 60\%. I set the depreciation rate at $\delta=0.025$, implying an annual depreciation rate of $10 \%$, which is commonly used in the literature. I set the steady state value of the trade balance (tb)-to-GDP ratio (tby) to $0 \%$, which is based on the sample mean of $-0.03 \%$.

As explained in Section 3, it is not the degree of relative risk aversion but the EIS that governs the movements of the variables in the model, and the model with the CRRA utility function and the model with recursive utility are seemingly equivalent in the log linearized environment. Thus, just for purposes of comparison, I set the value of $\gamma$ to unity in the case of the model with the CRRA utility function, which virtually means setting the EIS to unity. In the case of the model with recursive utility, the parameter $\gamma$ actually plays no role, because it does not appear in the log linearized system of the model. Thus, I simply set it to two.

\subsection{Bayesian Estimation and Simulation Results}

For the estimation and simulation, I do a Bayesian estimation. I execute the Bayesian estimation in Dynare version 4.2.2. Readers who are interested in the details of the estimation are referred to Griffoli's (2007-2008) Dynare User Guide. 
One thing that I should note here is that this version of Dynare does not allow the higher-order approximation of the model for the estimation. However, it is well known that log linearization is good enough if the main focus of the research is not on welfare analysis or investigation of the financial market but on examining the business cycle.

Table 2 reports the parameter values, both calibrated and estimated from the Bayesian estimation. The model data are simulated 300,000 times. The measurement equations for $Y_{t}, C_{t}, I_{t}$, and $\mathrm{TBY}_{t}$ are given by

$$
\begin{array}{r}
g_{Y t}=\underbrace{\Delta \log Y_{t}}_{\text {observed }}=\underbrace{\log \left(y_{t}\right)-\log \left(y_{t-1}\right)+\log \left(g_{t-1}\right)}_{\text {model }}, \\
g_{C t}=\underbrace{\Delta \log C_{t}}_{\text {observed }}=\underbrace{\log \left(c_{t}\right)-\log \left(c_{t-1}\right)+\log \left(g_{t-1}\right)}_{\text {model }}, \\
g_{I t}=\underbrace{\Delta \log I_{t}}_{\text {observed }}=\underbrace{\log \left(i_{t}\right)-\log \left(i_{t-1}\right)+\log \left(g_{t-1}\right)}_{\text {model }}, \\
\operatorname{TBY}_{t}=\underbrace{\mathrm{TB}_{t} / Y_{t}}_{\text {observed }}=\underbrace{\text { tb }_{t} / y_{t}}_{\text {model }}=\text { tby }_{t} .
\end{array}
$$

For the estimation, I use $g_{Y}, g_{C}, g_{I}$, TBY, and $r$ as observed variables, and consider a measurement error in each of them. I set the prior distribution for the $\mathrm{AR}(1)$ parameters for the shock process as a beta distribution, and the parameters with positive values as a gamma distribution. ${ }^{8}$ I set the prior distribution for the standard deviation of shock processes and the measurement errors for $g_{Y}, g_{C}, g_{I}$, TBY, and $r$ as an inverse gamma distribution. I set the prior mean of the EIS at 2.3, which is close to the values used in the literature. For example, Tallarini (2000) and Piazzesi and Schneider (2006) set $\psi$ at 1, and Bansal and Yaron (2004) set it at 1.5. Chen et al. (2013) estimate it to be $\approx 2$, and Binsbergen et al. (2012) estimate it to be 1.72 .

Table 3 reports the key moments simulated from the estimation. In Table 2, I set the prior mean of the EIS $(\psi)$ at 2.3 in the case of the model with RU, whereas I implicitly set it to unity in the case of the model with the CRRA utility function, because it equals the inverse of $\gamma$. The log data density from the model with the CRRA utility function is 1,454 and that from the model with RU is 1,386 . This implies that the overall performance of the model with the CRRA utility function is slightly better than that of the model with RU. However, the adoption of an EIS greater than one improves the performance of the simple RBC model at least in one important direction. It primarily raises the volatility of consumption relative to output. A higher EIS implies larger fluctuations in expected consumption growth given fluctuations in real interest rates. As far as the other second-order moments are concerned, the model with an EIS of unity performs better in explaining the correlations of investment with output, and both the autocorrelations of the trade balance and the real interest rate. ${ }^{9}$ 
TABLE 2. Parameter values both calibrated and estimated from Bayesian estimation of the Korean economy

\begin{tabular}{|c|c|c|c|c|c|}
\hline \multicolumn{6}{|c|}{ Calibrated parameters } \\
\hline$\alpha$ & \multicolumn{5}{|l|}{0.4} \\
\hline$g$ & \multicolumn{5}{|l|}{1.012} \\
\hline $1+r$ & \multicolumn{5}{|l|}{1.014} \\
\hline$\gamma, \psi$ & \multicolumn{5}{|c|}{$\gamma=1 / \psi=1$ (CRRA) $\gamma=2, \psi=$ see below (RU) } \\
\hline$\beta$ & \multicolumn{5}{|c|}{$0.998 \Leftarrow \beta=\frac{g^{\frac{1}{\psi}}}{1+r}(\mathrm{CRRA}), 0.991 \Leftarrow \beta=\frac{g^{\frac{1}{\psi}}}{1+r}(\mathrm{RU})$} \\
\hline $\mathrm{TB} / \mathrm{Y}$ & \\
\hline \multirow[t]{2}{*}{$\delta$} & \multicolumn{5}{|l|}{0.025} \\
\hline & $\begin{array}{l}\text { Prior } \\
\text { mean }\end{array}$ & $\begin{array}{c}\text { Posterior } \\
\text { mean }\end{array}$ & $90 c$ & C.I. & $\begin{array}{c}\text { Prior } \\
\text { distribution }\end{array}$ \\
\hline \multicolumn{6}{|c|}{ Estimated parameters (CRRA) } \\
\hline$\kappa$ & 3.0 & 3.42 & 3.25 & 3.60 & gamma \\
\hline$\phi$ & 0.01 & 0.003 & 0.002 & 0.004 & gamma \\
\hline$\rho_{A}$ & 0.8 & 0.978 & 0.970 & 0.986 & beta \\
\hline$\rho_{g}$ & 0.8 & 0.853 & 0.785 & 0.910 & beta \\
\hline$\sigma_{A}$ & 0.01 & 0.029 & 0.024 & 0.034 & inverse gamma \\
\hline$\sigma_{g}$ & 0.01 & 0.006 & 0.004 & 0.008 & inverse gamma \\
\hline$\sigma_{g_{Y}}$ & 0.01 & 0.011 & 0.007 & 0.015 & inverse gamma \\
\hline$\sigma_{g_{C}}$ & 0.01 & 0.015 & 0.013 & 0.018 & inverse gamma \\
\hline$\sigma_{g_{I}}$ & 0.01 & 0.017 & 0.007 & 0.027 & inverse gamma \\
\hline$\sigma_{\mathrm{TBY}}$ & 0.01 & 0.005 & 0.003 & 0.006 & inverse gamma \\
\hline$\sigma_{r}$ & 0.01 & 0.004 & 0.004 & 0.005 & inverse gamma \\
\hline \multicolumn{6}{|c|}{ Estimated parameters (RU) } \\
\hline$\kappa$ & 3.0 & 4.07 & 3.80 & 4.44 & gamma \\
\hline$\phi$ & 0.01 & 0.002 & 0.002 & 0.002 & gamma \\
\hline$\psi$ & 2.3 & 2.30 & 2.28 & 2.32 & gamma \\
\hline$\rho_{A}$ & 0.8 & 0.943 & 0.914 & 0.973 & beta \\
\hline$\rho_{g}$ & 0.8 & 0.851 & 0.755 & 0.956 & beta \\
\hline$\sigma_{A}$ & 0.01 & 0.016 & 0.013 & 0.019 & inverse gamma \\
\hline$\sigma_{g}$ & 0.01 & 0.004 & 0.002 & 0.005 & inverse gamma \\
\hline$\sigma_{g_{Y}}^{\delta}$ & 0.01 & 0.009 & 0.006 & 0.012 & inverse gamma \\
\hline$\sigma_{g_{C}}$ & 0.01 & 0.012 & 0.010 & 0.014 & inverse gamma \\
\hline$\sigma_{g_{I}}$ & 0.01 & 0.021 & 0.015 & 0.026 & inverse gamma \\
\hline$\sigma_{\mathrm{TBY}}^{\delta t}$ & 0.01 & 0.005 & 0.003 & 0.006 & inverse gamma \\
\hline$\sigma_{r}$ & 0.01 & 0.014 & 0.012 & 0.016 & inverse gamma \\
\hline
\end{tabular}

Note: Observed variables in the estimation: $g_{Y}, g_{C}, g_{I}$, TBY, and $r$.

Having an EIS greater than one is a controversial issue in macroeconomics. The $90 \%$ confidence interval of the EIS, $\psi$, ranges from 2.28 to 2.32. This interval does not include one. If the $90 \%$ confidence interval includes one, we cannot strongly exclude the possibility of the EIS being one. This is indirect evidence that we cannot reject the hypothesis that the EIS should be greater than one in order to explain Korean business cycles. 
TABLE 3. The key moments from Bayesian estimation of the Korean economy

\begin{tabular}{lrrr}
\hline & & \multicolumn{2}{c}{ Model } \\
\cline { 3 - 4 } Moments & Data & \multicolumn{1}{c}{ CRRA } & \multicolumn{1}{c}{ RU } \\
\hline$\sigma(c) / \sigma(y)$ & 1.25 & 0.94 & 1.22 \\
$\sigma(i) / \sigma(y)$ & 2.11 & 1.23 & 2.05 \\
$\operatorname{corr}(\mathrm{tb}, y)$ & -0.66 & -0.01 & 0.09 \\
$\operatorname{corr}(r, y)$ & -0.14 & -0.25 & -0.02 \\
$\operatorname{corr}(c, y)$ & 0.84 & 0.97 & 0.74 \\
$\operatorname{corr}(i, y)$ & 0.81 & 0.94 & 0.45 \\
$\operatorname{corr}\left(y, y_{-1}\right)$ & 0.78 & 0.99 & 0.97 \\
$\operatorname{corr}\left(c, c_{-1}\right)$ & 0.84 & 0.99 & 0.82 \\
$\operatorname{corr}\left(i, i_{-1}\right)$ & 0.85 & 0.95 & 0.51 \\
$\operatorname{corr}($ tb, tb & 0.76 & 0.59 & 0.25 \\
$\operatorname{corr}\left(r, r_{-1}\right)$ & 0.59 & 0.46 & -0.00 \\
Log data density & & 1,454 & 1,386 \\
\hline
\end{tabular}

In sum, we can say that there are, to say the least, some elements of success in describing the Korean economy based on the simple RBC model both with EIS larger than one and with an error term for the interest rate process. It explains the relative volatility between consumption (investment) and output rather well. In addition, it can explain the acyclicality or the weak countercyclicality of the real interest rate.

\subsection{Importance of the Trend Component}

The relative importance of the trend (growth) component can be measured as

$$
\frac{\operatorname{var}\left[(1-\alpha) g_{t}\right]}{\operatorname{var}\left(\Delta \log \mathrm{TFP}_{t}\right)}=\frac{(1-\alpha)^{2} \sigma_{g}^{2} /\left(1-\rho_{g}^{2}\right)}{2 \sigma_{A}^{2} /\left(1+\rho_{A}\right)+(1-\alpha)^{2} \sigma_{g}^{2} /\left(1-\rho_{g}^{2}\right)}
$$

From Table 2, we can figure out that it is 0.061 in the case of the model with CRRA utility $\left(\gamma=\frac{1}{\psi}=1\right)$ and 0.063 in the case of the model with RU (prior mean of the EIS, $\psi=2.3$ ). This means that the trend component explains a small fraction (about $6 \%$ ) of the movements of output.

Table 4 reports the variance decomposition of the RBC model with RU. From the variance decomposition, we can confirm that most fluctuations of output are due to the transitory technology shock. However, fluctuations in consumption and investment are affected by both transitory and growth components. It is also noticeable that most of the fluctuations in the trade balance and the real interest rates are due to the error term for the interest rate process, $\varepsilon_{r}$. Thus, we can say that different shocks are responsible for the movements of different variables. 
TABLE 4. Variance decomposition of the RBC model with recursive utility

\begin{tabular}{lrrr}
\hline Variables/shocks & \multicolumn{1}{c}{$\varepsilon_{A}$} & \multicolumn{1}{c}{$\varepsilon_{g}$} & \multicolumn{1}{c}{$\varepsilon_{r}$} \\
\hline$y$ & 90.4 & 9.4 & 0.2 \\
$c$ & 39.9 & 44.7 & 15.4 \\
$i$ & 32.8 & 25.7 & 41.5 \\
$\mathrm{tb}$ & 2.2 & 29.4 & 68.4 \\
$r$ & 0.1 & 0.2 & 99.8 \\
\hline
\end{tabular}

Then what is the error term for the interest rate process, $\varepsilon_{r}$ ? In order to answer this question, I turn to discussions of models with financial frictions.

\section{MODELS WITH FINANCIAL FRICTIONS}

Neumeyer and Perri (2005), Uribe and Yue (2006), Garcia-Cicco et al. (2010), and Chang and Fernandez (2013), among others, argue that the AG-type model supplemented with financial frictions does a better job of explaining the stylized facts in emerging-economy business cycles. Thus, I add various financial frictions to the baseline AG-type model from the preceding section and see whether they improve the performance of the baseline model.

There are many types of financial frictions in the literature. The so-called endogenous risk premium channel assumes that the country risk premium is endogenously related to the domestic state of the economy. For example, the country risk premium goes down if the market expects higher productivity or higher growth in the future. Specifically, I will consider the following case: ${ }^{10}$

$$
r_{t}=r^{*}+\phi\left[\exp \left(d_{t}-\bar{d}\right)-1\right]-\eta E_{t} \exp \left(a_{t+1}-1\right)+\varepsilon_{r t}
$$

Here, the country risk depends inversely on the expected productivity, $a_{t+1}$. This case is considered in Neumeyer and Perri (2005) and Faia and Monacelli (2007) in a different context, and in Chang and Fernandez (2013), among others. One advantage of this type of risk premium is that we can have a countercyclical risk premium; the risk premium goes down if the market expects higher productivity in the future.

Garcia-Cicco et al. (2010) considers a different formulation of the risk premium:

$$
r_{t}=r^{*}+\phi\left[\exp \left(d_{t}-\bar{d}\right)-1\right]+\exp \left(\mu_{t}-1\right)-1
$$

where

$$
\ln \mu_{t}=\rho_{\mu} \ln \mu_{t-1}+\varepsilon_{\mu t},-1<\rho_{\mu}<1,
$$

with $\varepsilon_{\mu t} \sim N\left(0, \sigma_{\mu}\right)$. I call this the exogenous risk premium channel, because it simply adds another shock, $\mu_{t}$, to the baseline model of the risk premium. It may stem from financial imperfections, which lead to stochastic shifts in the country 
TABLE 5. Key moments, variance decomposition of the RBC model with endogenous risk premium channel

\begin{tabular}{|c|c|c|c|}
\hline \multicolumn{2}{|l|}{ Moments } & Data & Model \\
\hline \multicolumn{2}{|l|}{$\sigma(c) / \sigma(y)$} & 1.25 & 1.07 \\
\hline \multicolumn{2}{|l|}{$\sigma(i) / \sigma(y)$} & 2.11 & 2.18 \\
\hline \multicolumn{2}{|l|}{$\operatorname{corr}(\mathrm{tb}, y)$} & -0.66 & -0.28 \\
\hline \multicolumn{2}{|l|}{$\operatorname{corr}(r, y)$} & -0.14 & -0.74 \\
\hline \multicolumn{2}{|l|}{$\operatorname{corr}(c, y)$} & 0.84 & 0.91 \\
\hline \multicolumn{2}{|l|}{$\operatorname{corr}(i, y)$} & 0.81 & 0.71 \\
\hline \multicolumn{2}{|l|}{$\operatorname{corr}\left(y, y_{-1}\right)$} & 0.78 & 0.87 \\
\hline \multicolumn{2}{|l|}{$\operatorname{corr}\left(c, c_{-1}\right)$} & 0.84 & 0.85 \\
\hline \multicolumn{2}{|l|}{$\operatorname{corr}\left(i, i_{-1}\right)$} & 0.85 & 0.76 \\
\hline \multicolumn{2}{|l|}{$\operatorname{corr}\left(t b, t_{-1}\right)$} & 0.76 & 0.73 \\
\hline \multicolumn{2}{|l|}{$\operatorname{corr}\left(r, r_{-1}\right)$} & 0.59 & 0.50 \\
\hline \multicolumn{4}{|c|}{ Variance decomposition $(\%)$} \\
\hline Variables/shocks & $\varepsilon_{A}$ & $\varepsilon_{g}$ & $\varepsilon_{r}$ \\
\hline$y$ & 89.7 & 10.3 & 0.0 \\
\hline$c$ & 63.0 & 36.0 & 1.1 \\
\hline$i$ & 79.2 & 19.0 & 1.8 \\
\hline tb & 41.3 & 51.5 & 7.2 \\
\hline$r$ & 61.8 & 0.3 & 38.0 \\
\hline Log data density & & & 1,430 \\
\hline
\end{tabular}

premium that are uncorrelated with the state of domestic fundamentals such as $a_{t}$ and $g_{t}$.

Among the various types of financial frictions, I report only the case of the endogenous risk premium channel in Table 5. The exogenous risk premium channel cannot be differentiated from the baseline model with an error term for the real interest rate process, so the estimation results turn out not to be qualitatively different. Table 5 reports the log data density, the key moments simulated from the estimation, and the variance decompositon of the RBC model with the endogenous risk premium channel. ${ }^{11}$ The log data density is 1,430 , which is in between the model with the CRRA utility function and the model with RU. Compared with the RBC model with RU, the RBC model with the endogenous risk premium channel better explains the autocorrelations of each variable and the correlations of each variable with output except the correlation of $r$ and $y$. The RBC model with the endogenous risk premium channel implies a too strong countercyclicality of the real interest rate. If we compare the variance decompostions reported in Tables 4 and 5 , the contribution of $\varepsilon_{r}$ in explaining the movements of each variable becomes significantly smaller in Table 5, where I take the endogenous risk premium channel into consideration. It is almost negligible except the case of $r$, where $\varepsilon_{r}$ still explains about $38 \%$ of the movements in $r$. Table 5 implies that $\varepsilon_{r}$ represents 
mostly the endogenous risk premium channel reflected in equation (30). As a result, the contribution of the transitory productivity shock, $\varepsilon_{A}$, in explaining the movements of each variable significantly increases.

\section{APPLICATION TO THE ARGENTINE DATA}

Some readers may wonder whether the main message of this paper-that the higher EIS can better explain the excess volatility of consumption relative to output in Korean business cycles_-can also be applied to other emerging economies such as Argentina or Mexico. Thus, I do a Bayesian estimation of the Argentine economy as an example in this section.

Several remarks are in order before I report the estimation results for the Argentine economy. First, I follow Garcia-Cicco et al. (2010) except that I adopt the Cobb-Douglas utility function instead of Greenwood et al.'s (1988) utility function. The estimation results do not change qualitatively when I use exactly the same model as Garcia-Cicco et al. (2010) where Greenwood et al.'s (1988) utility function is used instead of the Cobb-Douglas utility function. Second, Garcia-Cicco et al. (2010) use $g_{Y}, g_{C}, g_{I}$, and TBY as observed variables and do Bayesian estimation. They do not use the real interest rate data in the estimation, whereas I use them as one of the observed variables in the estimation of the Korean economy. It is because the original motivation of this paper is to explain the excess volatility of consumption relative to output combined with both a relatively large mean growth rate of output and low real interest rates in Korea. Here, I use the same data used for Garcia-Cicco et al. (2010), because I do not have the real interest rate data for Argentina.

For the estimation, I use exactly the same calibrated values as in Table 2 of Garcia-Cicco et al. (2010); I set $\alpha=0.32, \beta=0.9224, \delta=0.1225, \phi$ (their $\psi)=0.001, \bar{d}=0.007$. I use $g_{Y}, g_{C}, g_{I}$, and TBY as observed variables, and consider a measurement error in each of them. I set the prior distribution of each parameter to those values reported in Table 3 of Garcia-Cicco et al. (2010). In order to see what happens when the EIS gets larger, I set the value of $\gamma$ at 2, 1 , and $1 / 2$ for the purpose of comparison, which corresponds to the EIS of 1/2, 1 , and 2 , respectively, in the model with RU.

Table 6 reports the key second moments simulated from the estimation. As the EIS becomes larger, or equivalently, the parameter $\gamma$ becomes smaller, the correlation between the output growth and the trade balance to output ratio (tby) becomes more negative, the volatility of tby becomes smaller, and the correlation between consumption (investment) growth and tby becomes more negative. There are no significant changes in the volatilities and autocorrelations of variables: $g_{Y}, g_{C}, g_{I}$. This can be explained as follows: As the EIS becomes larger, consumption fluctuates more to smooth consumption, and the trade balance tends to move more in the direction opposite to output. This makes both the correlation between output growth and tby and the correlation between consumption (investment) growth and tby more negative. However, a higher EIS does not lead to the increased volatility 
TABLE 6. The key moments from Bayesian estimation of the Argentine economy

\begin{tabular}{lrrrr}
\hline Moments & Data & $\gamma=2$ & $\gamma=1$ & $\gamma=1 / 2$ \\
\hline$\sigma\left(g_{Y}\right)$ & 5.3 & 5.5 & 5.5 & 5.5 \\
$\sigma\left(g_{C}\right)$ & 7.5 & 10.3 & 10.3 & 10.0 \\
$\sigma\left(g_{I}\right)$ & 20.4 & 12.0 & 12.1 & 12.1 \\
$\sigma(\mathrm{TBY})$ & 5.2 & 56.7 & 39.1 & 28.6 \\
$\operatorname{corr}\left(g_{Y}, g_{C}\right)$ & 0.72 & 0.42 & 0.42 & 0.43 \\
$\operatorname{corr}\left(g_{Y}, g_{I}\right)$ & 0.67 & 0.57 & 0.57 & 0.57 \\
$\operatorname{corr}\left(g_{Y}, \mathrm{TBY}\right)$ & -0.04 & -0.09 & -0.14 & -0.19 \\
$\operatorname{corr}\left(g_{C}, \mathrm{TBY}\right)$ & -0.27 & -0.12 & -0.17 & -0.22 \\
$\operatorname{corr}\left(g_{I}, \mathrm{TBY}\right)$ & -0.19 & -0.16 & -0.23 & -0.31 \\
$\operatorname{corr}\left(g_{Y}, g_{Y-1}\right)$ & 0.11 & 0.63 & 0.63 & 0.63 \\
$\operatorname{corr}\left(g_{C}, g_{C-1}\right)$ & -0.01 & 0.00 & 0.00 & 0.00 \\
$\operatorname{corr}\left(g_{I}, g_{I-1}\right)$ & 0.32 & 0.11 & 0.11 & 0.11 \\
$\operatorname{corr}(\mathrm{TBY}, \mathrm{TBY}-1)$ & 0.58 & 0.99 & 0.97 & 0.94 \\
\hline
\end{tabular}

Note: The model data were simulated 300,000 times. Calibrated parameter values and estimated posterior medians used for the simulations are from Tables 2 and 3 of Garcia-Cicco et al. (2010).

of consumption relative to output (or the volatility of consumption growth) in the Argentine data. This may be because Garcia-Cicco et al.'s (2010) parameterization and estimation are best suited to explaining the second moments of the growth variables. The volatility of consumption relative to output depends not only on the EIS but also on the other parameters such as $\rho_{A}, \rho_{g}$, and $\phi$, as discussed in Garcia-Cicco et al. (2010). Another possibility is that the estimation does not include the real interest rate data as one of the observed variables. Or it may be because of something else. Unfortunately, I do not have the answer to this issue, and I leave it for future research.

\section{RISKY STEADY STATE}

Most previous business cyle research takes the approach of log linearizing the RBC (and/or DSGE) models around the deterministic steady state. However, Coeurdacier et al. (2011) show that taking the stochastic steady state into consideration may improve the performance of a model, especially in welfare and/or portfolio decision analyses. They explicitly define the risky steady state as "the point where agents choose to stay at a given date if they expect future risk and if the realizations of shocks is zero at this date." Thus, I examine whether considering the risky steady state can be an alternative to the EIS being larger than one in the log linearized model with the CRRA utility function in explaining the excess volatility of consumption relative to output in emerging-economy business cycles. ${ }^{12}$

It is not clear whether taking the risky steady state into account will increase the volatility of consumption relative to output. Let us suppose that there is a 
positive income shock. The more persistent the shock is, the more consumption will increase. It will exacerbate the trade balance and increase foreign borrowing and the risk premium. A higher risk premium will then discourage foreign borrowing and stabilize consumption. At the same time, the risky steady state leads to a precautionary motive for savings. The precautionary motive for savings will reduce consumption in the risky steady state. Thus, it is difficult to say a priori whether considering the risky steady state will increase the volatility of consumption relative to output.

Following de Groot (2014), I solve a first-order approximation of the RBC model in Subsection 3.1 around a second-order approximation of the model's risk-adjusted steady state. ${ }^{13}$ The risk-adjusted correction terms appear in the forward-looking equations: the definition of the stochastic discount factor, the Euler equation (10), and the capital Euler equation (11). More specifically, these three equations are modified at the risky steady state as follows:

$$
\begin{gathered}
m \equiv \frac{\beta}{g^{\gamma}}+M_{1}, \\
1=\frac{\beta}{g^{\gamma}} \cdot r+M_{2}, \\
1=\frac{\beta}{g^{\gamma}}\left[1-\delta+\alpha\left(\frac{g}{k}\right)^{1-\alpha}\right]+M_{3},
\end{gathered}
$$

where the lowercase $m$ denotes the stochastic discount factor and the capital $M \mathrm{~s}$ the risk-adjusted steady state correction terms (the second-order terms).

Table 7 reports the parameter values used for the simulation, the volatility of consumption (investment) relative to output, and the correlation between the trade balance (the real interest rate) and output. I set most of the parameter values close to the posterior mean of the RBC model with the CRRA utility function reported in Table 2, except $\kappa$ and $\phi$. I set $\kappa=1$ and $\phi=0.1 .^{14}$ The volatility of consumption relative to output is 0.93 in the case of the risky steady state, which is slightly larger than that in the deterministic steady state, and the volatility of investment relative to output is 1.35 , which is slightly smaller than that in the deterministic steady state. Thus, we can say that considering the risky steady state does not significantly improve the performance of the log linearized RBC model with the CRRA utility function around the deterministic steady state as far as the excess volatility of consumption relative to output is concerned.

\section{CONCLUSION}

Previous studies considered Korean data in pointing out the stylized facts in emerging-economy business cycles: excess volatility of consumption relative to output, a strong negative correlation between output and the trade balance, and a negative correlation between output and the real interest rate. However, their main focus is on Latin American economies such as Mexico and Argentina. 
TABLE 7. Calibration and the key moments from the RBC model with the risky steady state

\begin{tabular}{|c|c|c|c|}
\hline \multicolumn{4}{|c|}{ Calibrated parameters } \\
\hline$\alpha$ & \multicolumn{3}{|l|}{0.4} \\
\hline$g$ & \multicolumn{3}{|l|}{1.012} \\
\hline $1+r$ & \multicolumn{3}{|l|}{1.014} \\
\hline$\gamma, \psi$ & \multicolumn{3}{|c|}{$\gamma=1 / \psi=1$} \\
\hline$\beta$ & \multicolumn{3}{|c|}{$0.998 \Leftarrow \beta=\frac{g^{\frac{1}{\psi}}}{1+r}(\mathrm{CRRA})$} \\
\hline $\mathrm{TB} / \mathrm{Y}$ & \multicolumn{3}{|c|}{0.0} \\
\hline$\delta$ & \multicolumn{3}{|l|}{0.025} \\
\hline$\kappa$ & \multicolumn{3}{|l|}{1.0} \\
\hline$\phi$ & \multicolumn{3}{|l|}{0.1} \\
\hline$\rho_{a}$ & \multicolumn{3}{|l|}{0.95} \\
\hline$\rho_{g}$ & \multicolumn{3}{|l|}{0.85} \\
\hline$\sigma_{a}$ & \multicolumn{3}{|l|}{0.025} \\
\hline$\sigma_{g}$ & \multicolumn{3}{|l|}{0.006} \\
\hline$\sigma_{g_{Y}}$ & \multicolumn{3}{|l|}{0.010} \\
\hline$\sigma_{g_{C}}$ & \multicolumn{3}{|l|}{0.015} \\
\hline$\sigma_{g_{I}}$ & \multicolumn{3}{|l|}{0.02} \\
\hline$\sigma_{\mathrm{TBY}}$ & \multicolumn{3}{|l|}{0.005} \\
\hline$\sigma_{r}$ & \multicolumn{3}{|l|}{0.004} \\
\hline \multicolumn{4}{|c|}{ Estimated risk-adjusted correction terms } \\
\hline$M_{1}$ & \multicolumn{3}{|c|}{0.00009516} \\
\hline$M_{2}$ & \multicolumn{3}{|c|}{0.00003254} \\
\hline$M_{3}$ & \multicolumn{3}{|c|}{0.00002680} \\
\hline Moments & Data & $\begin{array}{l}\text { Deterministic } \\
\text { steady state }\end{array}$ & $\begin{array}{c}\text { Risky } \\
\text { steady state }\end{array}$ \\
\hline$\sigma(c) / \sigma(y)$ & 1.25 & 0.82 & 0.93 \\
\hline$\sigma(c) / \sigma(y)$ & 2.11 & 1.52 & 1.35 \\
\hline $\operatorname{corr}(y, \mathrm{tb})$ & -0.66 & -0.29 & -0.28 \\
\hline $\operatorname{corr}(y, r)$ & -0.14 & -0.75 & -0.77 \\
\hline
\end{tabular}

This paper explicitly focuses on describing and estimating the Korean economy. In order to do that, I incorporated a recursive utility into an AG-type RBC model in order to circumvent a situation where the discount factor becomes larger than one when the Korean economy is calibrated. This situation is due to the fact that the sample mean of the real interest rate is relatively low and the sample mean growth rate is relatively large. Recursive utility allows us to separate the degree of relative risk aversion from the EIS. The log linearization of the model with recursive utility shows that it is not the degree of relative risk aversion but the EIS that governs the movements of the variables in the model. This makes room for setting $\gamma$, conventionally interpreted as the degree of relative risk aversion in the case of the CRRA utility function, to be less than one, because it can be now 
interpreted as the inverse of the EIS. It also suggests that the model with the CRRA utility function, combined with $\gamma$ less than one, can produce the same results as the model with recursive utility where the EIS is larger than one.

Bayesian estimation based on Korean data shows that there are some elements of success in describing the Korean economy based on the simple RBC model, both with the EIS larger than one and with an error term for the real interest rate process. It explains the relative volatility between consumption (investment) and output fairly well. It also shows acyclicality or a weak countercyclicality of the real interest rate observed in the Korean data. The estimation results further imply that the contribution of the trend component is small (about 6\%) in explaining the movements of output.

I also examined whether the same model supplemented with some aspects of financial frictions can account for the success of the baseline model with an error term for the real interest rate process. As a simple way to reflect financial frictions, I follow previous research and assume that the domestic real interest rate depends negatively on the expected (transitory) productivity shock. I call this the endogenous risk premium channel. Simulation results suggest that the error term for the real interest rate process mostly reflects the endogenous risk premium channel. The endogenous risk premium channel further implies that the output and the trade balance are negatively correlated.

Though the results are encouraging, they are not very satisfactory. In particular, the correlation between output and the trade balance is not strongly countercyclical, and the autocorrelations of the trade balance and the real interest rate are not satisfactorily explained. Thus, in future research it would be interesting to introduce various mechanisms and/or frictions into the model to see if they can improve the explanatory power of the simple RBC model.

To see whether the main message of this paper-that the higher EIS can better explain the excess volatility of consumption relative to output in Korean business cycles - can also be applied to other emerging economies, I do Bayesian estimation of the Argentine economy as an example. Unfortunately, the results are not encouraging. A higher EIS does not lead to the increased volatility of consumption relative to output (or the volatility of consumption growth) in the Argentine data. It may be because Garcia-Cicco et al. (2010)'s parameterization and estimation are best suited to explaining the second moments of the growth variables. The volatility of consumption relative to output depends not only on the EIS but also on the other parameters such as $\rho_{A}, \rho_{g}$, and $\phi$. Another possibility is that the estimation does not include the real interest rate data as one of the observed variables, whereas I include it as one of the observed variables in the case of Korea. Or it may be because of something else. Unfortunately, I do not have the answer to this issue and leave it for future research.

Finally, I examined whether considering the risky steady state can improve the performance of the simple RBC model in explaining the excess volatility of consumption relative to output in emerging-economy business cycles. It does not significantly improve the performance of the simple RBC model. It is not 
surprising in the sense that the second-order approximation in general does not qualitatively change the results from the business cycle analyses that are based on $\log$ linearization of a model.

\section{NOTES}

1. In the Korean data, the real interest rate is acyclical or weakly countercyclical, depending on measures of the real interest rate.

2. This is not surprising in view of the fact that Korea was the fastest-growing economy in the world from the 1960s to the early 1990s.

3. An and Li (2013), in an independent work, also notice that the log linearization of the model with recursive utility collapses to the model with the CRRA utility function. However, they do not explicitly show that it is not the degree of relative risk aversion but the EIS that governs the movements of the log linearized system of the model. Their main focus is on explaining the movements of both macroeconomic and financial variables, and they concentrate on the second-order approximation of the model with recursive utility.

4. AG's Korean data can be obtained at http://scholar.harvard.edu/gopinath/pages/data-and-codes. These data cover the period 1979:IV-2003:II.

5. Here GDP is measured as GDP net of government spending, because the model in Section 3 does not include government spending. If I use GDP including government spending, the volatility of consumption relative to output is higher than one for the whole sample period. Of course, even in this case, the excess volatility of consumption relative to output arises from the latter part of the sample.

6. Detrending log GDP per capita with a cubic trend as was done in Garcia-Cicco et al. (2010)'s Figure 1 also produces about five trend cycles for the whole sample.

7. Previous empirical studies, Garcia-Cicco et al. (2010) among others, also include crisis periods of Latin American economies. Theoretically, Boissay et al. (2013) suggest an RBC model that can generate banking crises.

8. For convenience, I simply call the error term for the interest rate process "measurement error." I will discuss later whether it reflects some aspects of financial frictions or represents a measurement error independent of them.

9. The model with the CRRA utility function in which $\gamma$ is set to the inverse of the EIS, $\psi(=2.3)$, should produce the same results as those reported in Table 3 under the column of the model with RU. This is actually the case.

10. I also considered $g_{t+1}$ instead of $a_{t+1}$, but the results do not change qualitatively from those reported in Tables 2 to 4 .

11. I set the prior distribution for $\eta$ in equation (30) as a gamma distribution with prior mean of 0.1 .

12. This analysis was suggested by an anonymous referee.

13. I am grateful to O. de Groot for making his codes available.

14. Otherwise, the model has difficulty in convergence, especially when I set $\phi$ to a value less than 0.1 .

\section{REFERENCES}

Aguiar, Mark and Gita Gopinath (2007) Emerging market business cycles: The cycle is the trend. Journal of Political Economy 115, 69-102.

An, Sungbae and Nan Li (2013) Measuring Intangible Capital with Uncertainty. Unpublished manuscript, Singapore Management University.

Bahng, Hong K. (2012) Accounting for Business Cycle Regularities in Emerging Economies. Unpublished thesis (Ph.D.). University of Rochester.

Bansal, Ravi and Amir Yaron (2004) Risks for the long run: A potential resolution of asset pricing puzzles. Journal of Finance 59(4), 1481-1509. 
Binsbergen, Jules H., Jesus Fernandez-Villaverde, Ralph S.J. Koijen, and Juan F. Rubio-Ramirez (2012) The term structure of interest rates in a DSGE model with recursive preference. Journal of Monetary Economics 59, 634-648.

Boissay, Frederic, Fabrice Collard, and Frank Smets (2013) Booms and Banking Crises. ECB WP 1514.

Boz, Emine, C. Bora Durdu, and Nan Li (2012) Emerging Market Business Cycles: The Role of Labor Market Frictions. IMF WP 12237.

Chang, Roberto and Andres Fernandez (2013) On the sources of aggregate fluctuations in emerging economies. International Economic Review 54, 1265-1293.

Chen, Xiaohong, Jack Favilukis, and Sydney C. Ludvigson (2013) An estimation of economic models with recursive preferences. Quantitative Economics 4, 39-83.

Coeurdacier, Nicolas, Helene Rey, and Pablo Winant (2011) The risky steady state. American Economic Review 101, 398-401.

de Groot, Oliber (2014) The risk channel of monetary policy. International Journal of Central Banking $10,115-160$.

Dew-Becker, Ian (2012) A Model of Time-Varying Risk Premia with Habits and Production. Job Market Paper, Harvard University.

Dew-Becker, Ian (2014) Bond pricing with a time-varying price of risk in an estimated medium-scale Bayesian DSGE model. Journal of Money, Credit and Banking 46, 837-888.

Epstein, Larry G. and Stanley E. Zin (1991) Substitution, risk aversion, and the temporal behavior of consumption and asset returns: An empirical analysis. Journal of Political Economy 99(2), 263-286.

Faia, Ester and Tommaso Monacelli (2007) Optimal interest rate rules, asset prices, and credit frictions. Journal of Business and Economic Studies 31, 3228-3254.

Garcia-Cicco, Javier, Roberto Pancrazi, and Martin Uribe (2010) Real business cycles in emerging countries. American Economic Review 100, 2510-2531.

Greenwood, J., Z. Hercowitz, and G.W. Huffman (1988) Investment capacity utilization, and the real business cycle. American Economic Review 78, 402-417.

Griffoli, Tommaso Mancini (2007-2008) Dynare User Guide: An Introduction to the Solution \& Estimation of DSGE Models. www.dynare.org.

King, Robert, Charles Plosser, James Stock, and Mark Watson (1991) Stochastic trends and economic fluctuations. American Economic Review 81, 819-840.

Neumeyer, Pablo A. and Fabrizio Perri (2005) Business cycles in emerging economies: The role of interest rates. Journal of Monetary Economics 52, 345-380.

Otsu, Keisuke (2008) A neoclassical analysis of the Korean crisis. Review of Economic Dynamics 11, 449-471.

Piazzesi, Monika and Martin Schneider (2006) Equilibrium yield curves. NBER Macroeconomics Annual, 389-442.

Tallarini, Thomas D. (2000) Risk-sensitive real business cycles. Journal of Monetary Economics 45, $507-532$.

Uribe, Martin and Vivian Z. Yue (2006) Country spreads and emerging countries: Who drives whom? Journal of International Economics 69, 6-36.

Weil, Philip (1989) The equity premium puzzle and the risk-free rate puzzle. Journal of Monetary Economics 24, 401-421. 